\title{
The Embodiment Humanization in the Planning and Design of the Tourist Resorts-A Case Study of Guian Hot Spring Resort
}

\author{
Chen Chuan, Shengwei Wang \\ Fuzhou Planning Design \& Research Institute, Fuzhou, China
}

Email address:

656905899@qq.com (Chen Chuan)

\section{To cite this article:}

Chen Chuan, Shengwei Wang. The Embodiment Humanization in the Planning and Design of the Tourist Resorts—A Case Study of Guian Hot Spring Resort. International Journal of Architecture, Arts and Applications. Vol. 4, No. 3, 2018, pp. 34-37.

doi: $10.11648 /$ j.ijaaa.20180403.11

Received: July 9, 2018; Accepted: August 14, 2018; Published: November 5, 2018

\begin{abstract}
At present, the tourists' demand for the humanization of tourism facilities is increasing day by day. The planning design and construction of China's resorts has not yet formed a complete set of humanized planning and design system. This paper summarized the resort of humanized design basic content and standard through the basic discussion. Take Guian hot spring resort as an example, it is an important role of the humanized design in resort in the new period. This paper expounded the basic principles and contents of humanization in environment, catering facilities, tourism transportation and other supporting facilities and services from four aspects. And this paper also summarized the current situation of humanized design of Guian hot spring resort, one of the largest hot spring tourism resorts in China.
\end{abstract}

Keywords: Resorts, Humanization, Planning and Design

\section{Meaning of Humanization}

Humanization is a concept which refers to the coordination of technology and human relations [1]. That is, the development of technology revolves around the human needs. The technology in this paper was in a broad sense, not just in one area. The characteristics of humanization means that the products can not only satisfy consumers' functional demands, but also satisfy their psychological needs. Humanization design is closely related to usability design. The humanized design pursued by resorts is to meet the requirements of usability design and adapting to the human nature. What is humanized design? The humanization of resorts contains two meanings.

Firstly, it means that the facilities of the resort, while showing the beauty and practicality, can also take into account the people-oriented design concept. The facilities must be designed reasonable, based on the tourists' needs and the habits of travel tours, from the perspective of health, happiness, comfort and other pleasurable body and mind.

Secondly, the humanization of tourism resorts is to provide quality services with humanistic care to tourists, so as to improve the satisfaction of them.

\section{Background and Basis of Humanized Planning and Design}

Currently, the tourism and holiday industry in China has been widely developed and promoted [2-6]. It's planning, design facilities supporting and service level are becoming more and more cultural, humanized and meticulous. However, because of the lack of the research, teaching materials and implementation and evaluation standards in this area, $t$, a very large number of resorts and company doesn't know much about humanized planning and design. Therefore, they can not plan and design a humanized tourist attractions or resorts effectively.

In China, the evaluation standard of the class series scenic spot and the resorts are the most representative reference for the humanized design and service in the national standard [7-8]. 


\section{The Concrete Embodiment of the Humanization in Resorts}

\subsection{Humanization of Accommodation}

As part of the important supporting facilities in resorts, accommodation is not only a place for tourists to stay, but also an important source of income for the Resorts.

First of all, the accommodation must meet the requirements of humanization design in its layout.

The accommodation and supporting services of the resorts was emergence and developed in order to meet the tourist's demand of sight-seeing travel, leisure and others, It is very important to improve the comfort of Hotels in resorts. their building structure should include humanized ventilation, daylighting, water supply and drainage, beautifying the environment and coordinating the environment.

Therefore, the Humanization requirements of the hotel's location are usually good air, environmental ecology, beautiful view landscape, the hotel scale is reasonable, and the Humanization design of the hotel facilities usually refers to the good ventilation, the ample lighting, the lobby facilities and services.

\subsection{Humanization of Catering Facilities}

The location of catering facilities should be scientifically planned and convenient for tourists to eat. The humanization of catering facilities is simply to provide more meticulous and thoughtful service on the basis of "people-oriented". It includes the convenience and service level experienced by tourists from the scenic spots to the place to leave. Providing tangible and intangible humanized service to the customers. The humanized service of food and beverage emphasizes the wholehearted intention to serve the customer, fully understands the guest's request and mentality, carefully observes the behavior of the customer, provides the service sincerely, and truly embodies the humanization of the catering facilities.

As a result, the planning and location of catering facilities should be humanized, and its size should be appropriate. The design requirements of tourist restaurants are usually good air, environmental ecology and beautiful view.

\subsection{Humanization of Tourist Traffic}

First, the road, walking path and other tourist traffics should have the humanized layout in design, and the path to the tourist attractions is convenient. They should be no detour, little bypass, less uphill, multi flat road and downhill [9-10]. They should design a diversified traffic road, use different forms of transportation, for example, arrange the electric vehicle in the tourist area, and fully cooperate. The operation of the battery car in the resort is more convenient and quick to serve the tourists S Second, the route to the service facilities such as the restaurant and hotel also requires convenience。 They should be no detour, little bypass, less slope, more flat road, and downhill. Third, the layout design of parking lot.
Firstly Its size should meet passenger flow and not too crowded. Secondly, the parking lot should be ecological, greening sunshade, shelter from rain. Furthermore, the parking lot should have corridor, tourist toilets, catering and other sexual matching.

\subsection{Humanization of Other Supporting Facilities and Services}

In tourist areas, tourists often find themselves in a foreign land, often having difficulties and obstacles in language, habits, life and daily living. Tourist areas provide timely multi lingual services, such as English, Japanese and Korean, and should also pay attention to Chinese languages such as Cantonese and Min Nan. In addition to the foreign language logo in each tourist area, the different language guides in the tourist area should be reasonably arranged according to the proportion of the foreign tourists they receive. In addition, the service facilities and personnel of the disabled service, rescue service, medical service, security police, post office bank and so on should be provided. The tourist areas should also improve the level of information service in tourist resorts and provided information and reservation services for tourists.

\subsection{The Humanization of the Environment in the Tourist Area}

The tourist environment takes measures such as maintaining or restoring the vegetation around the holiday resort and improving the greening rate of the resort, so as to make the tourist resort ecological and warm [11-13]. Secondly, the scientific measures of air purification in the resort area make the air quality of the tourist resort reach a certain standard and the annual average index of various pollutants is less than a certain standard. The standard is less than the highest level of the A-level standard; actively cooperate with the government to protect and improve the water resources in the tourist area and strive to maintain and improve the drainage facilities in the tourist area, so that the environmental quality of the surface water area of the tourist resort is in conformity up to the standard.

The environmental requirements should meet the excellent standards. The accommodation and surrounding noise environment in the tourist resort. In the planning and design of the resort, the average volume rate of the built-up area is maintained at a more comfortable and reasonable level such as $0.4 \sim 0.8$; the average green land rate in the built-up area of the tourist resort should be greater than or equal to 0.5 ; The overall style and features of the interior architecture and landscape are integrated with the environment, with prominent local characteristics; the vegetation in the area should be mostly native species; the environmental decoration materials should be adopted [14]. At the same time, the decoration materials for the holiday facilities are required, and the indoor decoration and decoration materials meet the requirements of the ring and air quality. 


\section{Taking the Tourist Resort of GUI AN Hot Spring as an Example}

The Guian hot spring is located in the village of Guian village, pan Du Township, Lianjiang county. It is known as "the hometown of hot springs in Fujian". It is one of the most famous geothermal concentrated areas in the country. The reasonable exploitation of the hot spring day in the village of Guian is 7000 tons, and the water temperature is $63 \sim 92 \mathrm{C}$, which is rich in several kinds of mineral elements beneficial to the human body. It has been developed and used in the year of 1057. The total planning area of GUI an hot spring resort is 106 square kilometers. It is a garden style hot spring resort with leisure holiday, hot spring bath, conference training and fitness and entertainment [15]. The Guizhou hot spring resort has become an important part of the tourism image of the "capital of hot springs" in Fuzhou [16]. Its humanization and sustainable development are related to the construction and maintenance of the "hot spring capital" tourist brand in Fuzhou. In this paper, two aspects of accommodation facilities and transportation facilities are analyzed and evaluated to illustrate the importance of humanized planning and design for resorts.

\subsection{The Humanization of Accommodation Facilities}

There are 4 main hotels in the planning area: the Century Golden Resources hotel, the Springs Hotel in Xishan, the Springs Hotel of GUI an, the King World Hotel. The total bed number are about 2800 .

The Century Golden Resources Hotel and King World Hotel are five-star hotels, and there are no stars in the hotel. The proportion of accommodation and reception facilities above 3 stars or equivalent to above 3 stars is 50\%. It Provide spacious and comfortable service for high-end guests.

The Xishan Springs Hotel and GUI an Springs Hotel belong to the hot spring resort hotels. They are more comfortable The Century Golden Resources Hotel is a business holiday resort hotel. It has five star equipped facilities and also comfortable. The King World Hotel is a holiday resort hotel, equipped with five-star facilities and also comfortable. There are basically better adapted to the needs of consumers.

The Century Golden Resources Hotel and the King World Hotel are located in the business leisure area, the XISHAN Springs Hotel and the Guian Springs Hotel are in the hot spring resorts, which basically meet the requirements of the functional zoning and the beautiful air, environment, and beautiful landscape. It was very popular in the market. The hotel has a relatively quiet, beautiful scenery, good ecological environment, a good surrounding environment surrounded by mountains and rivers, tourism resort area can rely on a good base of ecological environment, and fully play the conditions of planning and designing humanized functions and facilities. For example, hotels and hot-spring houses can be hidden in broad daylight with the original bamboo forests and banana plan uses. (see Figure 1)

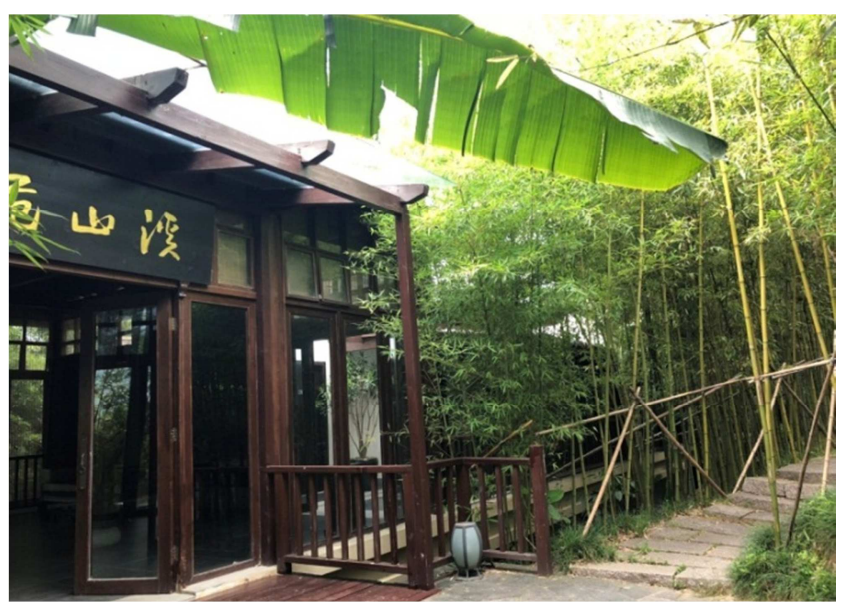

Figure 1. Bamboo forests, banana plan uses and hot-spring houses set each other off.

Their explored and used natural landscape conditions in a good environment surrounding the landscape to set up catering, tea bar, coffee bar and other supporting facilities. The vision including the sparkling surface, and create a humanized tourism atmosphere. (see Figure 2)

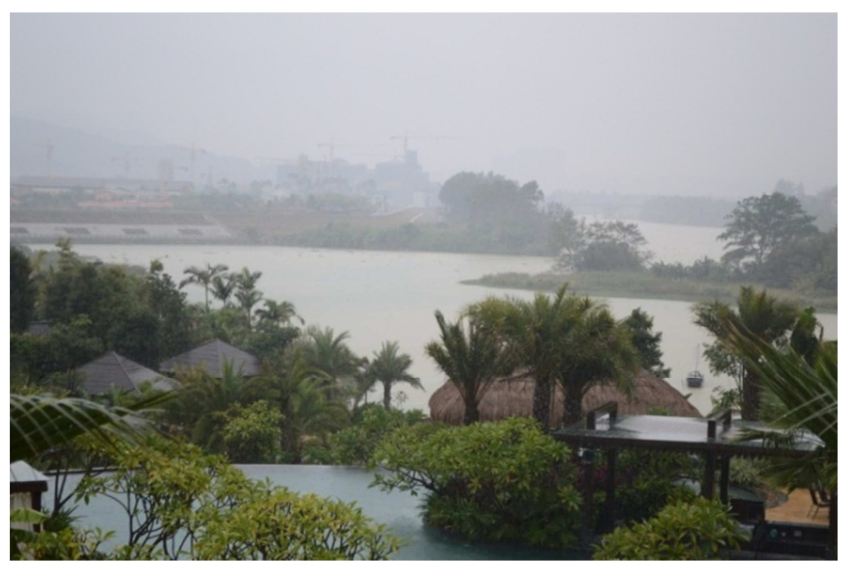

Figure 2. Humanized creation of the holiday atmosphere.

\subsection{Humanized Status of Tourism Transportation Service Facilities}

Parking lot layout and capacity: the parking lot in the area is basically with the hotel and the small scenic spots. There are basically suitable for their respective scenic spots, especially the Creek Mountain, the precious dragon and the precious Guinxin tiandi scenic area;

Due to the lack of humanized planning and design, there are many problems happened in the peak season. The small scenic spots are full, other tourist vehicles lack parking and no public parking is built in the macro scope. Many tourists have no humanized service in this area, feel inconvenient and complain.

The overall convenience of tourist traffic in Guian tourist resort, but because of the lack of overall consideration, there is no unified intra area traffic bus in the large area, which makes the tourists inconvenient to travel to different scenic spots.

The public pedestrian walkway in the area is not perfect 
enough, most sections of the pedestrian and car are mixed, the good slow line system is not established, and the humanized walking conditions in the tourist resort are lacking. On public transport and connecting traffic, tourists feel tired, tired and lack of human nature.

\subsection{Suggestions for Improvement of Humanized Design}

The Guian hot spring resort is a large tourist area with a small scenic area. Only a few scenic spots have its own battery car service. The whole large area should set up an electric car or a small bus in the area that is convenient for tourists and can connect the small scenic spots in series.

\subsection{For Example, the Parking Lot in Xishan Scenic Area Is Very Successful in Humanized Design}

The downhill parking lot in the Xishan scenic area, a part of the hotel accommodation, is an ecologically designed walkway on the sidewalk leading to the Xishan resort \& soup house. The bamboos are planted by the roadside, which can shading in the summer and also as a landscape view. It can make visitors feeling cool and comfortable. And give them a quiet winding path and visual experience. This humanized design has been praised by many tourists. (see Figure 3 )

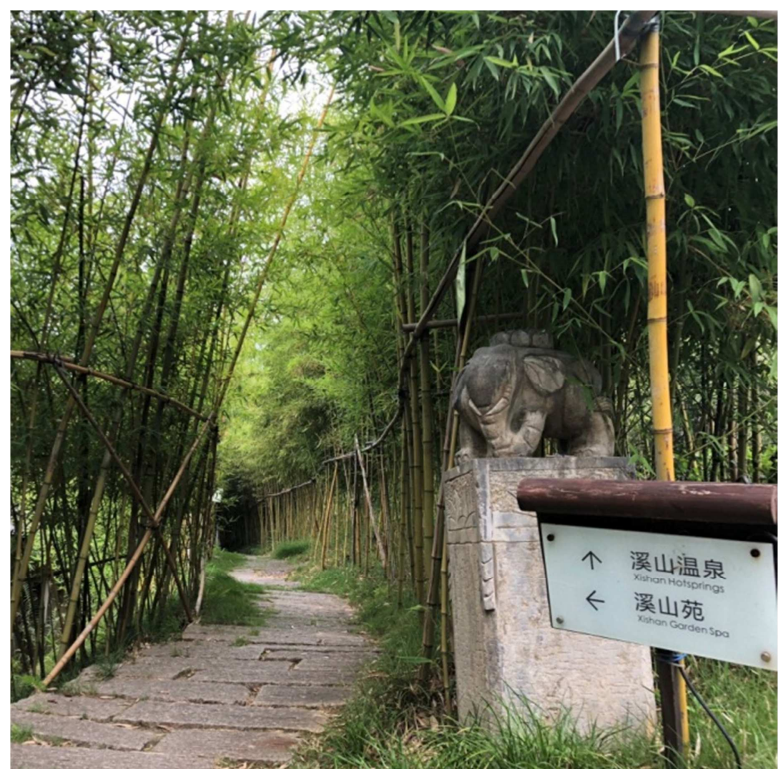

Figure 3. Convenient and graceful way to connect the holiday house after getting off the parking lot.

\section{Conclusion}

The humanization in the planning and design of the resorts is quite important. In fact, it can be seen that some nodes of Guian hot spring tourist resort are quite successful, but others have not yet reached the humanized request of tourist resort in a comprehensive way. As part of the 4A level of Guian hot spring resort, it is continuing to improve itself to 5A-level. It still has a lot of place to need to carry on the humanized planning design of the system and perfect in creating provincial tourism resort and even national resort.

\section{References}

[1] Wang Rusong. Systematization, naturalization, economy and humanization -- ecological transformation of urban habitat environment planning method $[\mathrm{J}]$. Urban environment and urban ecology, 2001, 1(3):1-5.

[2] Wan Min, Song Qingli, Ji Qian. Planning and design of butterfly tourism resort and its carrier -- a case study of planning and design of Suma dang national tourism resort in Lichuan city [J]. Central China architecture, 2017(1):82-88.

[3] Chen shi. Study on the planning and design method of tourism complex -- taking the planning of xintai lianhua mountain tourism resort as an example [J]. Chongqing architecture, 2014(4):38-41.

[4] Chen Dongtian, Wu Wei. Tourism resort planning for regional development - - Zhejiang Zhujiajian pointed island tourist resort development planning study [J]. Chinese garden, 2001, 17 (4): 42-44.

[5] Zhou Jianming. Development trend and planning characteristics of tourism resort [J]. International urban planning, 2003, 18(1):25-29.

[6] Zhou Jianming, Liu Cuipeng. Research on current situation and current trend of landscape tourism planning $[\mathrm{J}]$. Chinese garden, 2008, 24(11):29-33.

[7] GB/T 17775-2003 classification and evaluation of tourist attractions [S]. Beijing: China standard press, 2003.

[8] GB/T 26358-2010 tourism resort classification [S]. Beijing: China standard press, 2010.

[9] Sun Lifen, Zhang Xizhou. Discussion on the concept of coordinated design of tourism transportation facilities [J]. Planner, 2005, 21(7):98-100.

[10] Li Yang. Research on regional experience design of tourism and transportation based on user demand [J]. Comprehensive transportation, 2015(8):28-32.

[11] Zhang Yanfei, Zhu Haiying, Liu fang. Relationship between tourism environment, consumption habits and participation willingness of low-carbon tourism -- a case study of Wulingyuan natural heritage site $[\mathrm{J}]$. Journal of tourism studies, 2013, 28(6):56-64.

[12] Zaxi Zhuoma. Discussion on the development of suburban tourism resorts and sustainable development of ecological and environmental protection -- taking Lhasa as an example [J]. Science and technology, 2018(12):103-103.

[13] Zhou Qingfeng. Development strategy thinking of eco-tourism resort [J]. Tourism overview (second half), 2017(5): 237.

[14] Liu Jiaming. Ideas of landscape ecological design for tourism resort [J]. Human geography, 2004, 19(1):82-85.

[15] Li Xianhui. A brief analysis of the tourism resort planning based on the concept of eco-city -- a case study of the overall planning of Guian hot spring tourism resort [J]. Fujian architecture, 2015(6):28-30.

[16] Yang Shiyuan, Lin Jian. Fuzhou hot spring tourism development based on Haixi tourist area [J]. Journal of Quanzhou normal university, 2011, 29(4):64-67. 